\title{
International Journal of Genomics and Data Mining
}

Elbaz R, et al. Int J Genom Data Min 01: 114.

\section{Association of Apolipoprotein $C 3-455 T>C$ gene variant with Nonalcoholic Fatty Liver Disease in Obese Egyptians}

\author{
Rizk Elbaz ${ }^{1}$, Amal Elshaer², Mohamed Sheriff ${ }^{3}$, Yehia Othma ${ }^{4}$, Magdy Mahfouz ${ }^{5}$, Ahmad Settin ${ }^{6 *}$ \\ ${ }^{1}$ Professor, Biochemistry, Genetics Unit, College of Medicine, Mansoura University, Egypt \\ ${ }^{2}$ Candidate Master's degree, Biochemistry Department, Faculty of Science, Mansoura University, Egypt \\ ${ }^{3}$ Assistant Professor, Internal Medicine, Faculty of Medicine, Mansoura University, Egypt \\ ${ }^{4}$ Associate Professor, Molecular Biology, Faculty of Science, Mansoura University, Egypt \\ ${ }^{5}$ Professor, Biochemistry, Faculty of Science, Mansoura University, Egypt \\ ${ }^{6}$ Professor, Genetics, Faculty of Medicine, Mansoura University, Egypt
}

"Corresponding author: Ahmad Settin, Professor of Pediatrics and Genetics, Faculty of Medicine, Mansoura University, Egypt. Tel: +20223088371; +201009430440; Email: settin@mans.edu.eg, settin60@gmail.com

Citation: Elbaz R, Elshaer A, Sheriff M, Othma Y, Mahfouz M, et al. (2017) Association of Apolipoprotein C3 -455T>C gene variant with Nonalcoholic Fatty Liver Disease in Obese Egyptians. Int J Genom Data Min 01: 114. DOI: $10.29011 / 2577-0616.000114$

Received Date: 02 November, 2017; Accepted Date: 22 November, 2017; Published Date: 29 November, 2017

\begin{abstract}
Background: Apolipoprotein C3 (APOC3) gene polymorphisms were reported to be associated with non-alcoholic fatty liver disease (NAFLD), hyper-triglyceridaemia, and insulin-resistance.
\end{abstract}

Objective: This study was undertaken to test the association of APOC3 gene variants with liver dysfunction, abnormal lipid profile or insulin resistance in obese Egyptian subjects.

Methods: The study was carried out on 100 unrelated obese Egyptians affected with NAFLD. These cases were compared to 83 normal weight healthy controls. All participants were subjected to an estimation of their body mass index (BMI) in addition to liver and renal functions and lipid profile. In addition, polymerase chain reaction-restriction fragment length polymorphism (PCR-RFLP) was performed to detect APOC3 -455T $>$ C (rs2854116) and APOC3 -482C $>$ T (rs2854117) polymorphic genotypes.

Results: Cases showed a significantly higher frequency of the APOC3 -455 CC genotype than controls $(p=0.0003$, OR=5.33, $95 \% \mathrm{CI}=2.2-12.7)$. Also, the allelic frequency of the rare APOC3 $-455 \mathrm{C}$ allele was significantly higher among cases than controls $(\mathrm{p}=0.0001, \mathrm{OR}=2.35,95 \% \mathrm{CI}=1.5-3.6)$. On the other hand, cases showed a non-significant difference from controls regarding all APOC3 $-482 \mathrm{C}>\mathrm{T}$ genotypes and alleles. Although all obese cases were significantly showing affection of liver function, lipid profile and blood glucose levels compared to controls, they did not differ from each other in relation to their APOC3 genetic polymorphic types.

Conclusion: The polymorphism APOC3 -455T $>$ C but not the APOC3 -482C $>$ T in APOC3 gene was associated with NAFLD in Egyptian obese subjects. However, this polymorphism was not correlated to the degree of affection of liver function, lipid and glucose status. 


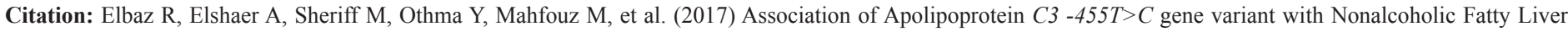
Disease in Obese Egyptians. Int J Genom Data Min 01: 114. DOI: 10.29011/2577-0616.000114

Keywords: Apolipoprotein C-III; Genetic; Obesity; Polymorphism; Non-alcoholic Fatty Liver Disease

\section{Introduction}

One of the most common chronic liver disorders is the nonalcoholic fatty liver disease (NAFLD) [1] which characterized by hepatic steatosis in the absence of alcohol consumption or other liver disorders [2] Both environmental and genetic factors contribute to the process of steatosis, steatohepatitis (NASH) and fibrosis. [3] Risk factors include obesity and type 2 diabetes/ insulin resistance. [4] Insulin resistance promotes peripheral adipose lipolysis, thereby increasing FFA flux to the liver, which drives hepatic triglyceride production [5]. Human studies have demonstrated peripheral adipose lipolysis, systemic free fatty acid levels, and de novo hepatic lipogenesis to be upregulated in subjects with NAFLD [6]. Fatty acid (palmitate) release from peripheral adipose deposits is increased approximately $35 \%$ in NAFLD patients compared to age, gender, and fat mass matched controls, and it accounts for approximately $60 \%$ of hepatic lipid in subjects with NAFLD. [6] De novo lipogenesis accounts for $25 \%$ of hepatic fat content in NAFLD subjects compared with $10 \%$ in obese hyper-insulinemic subjects and 5\% in healthy individuals. [7]

In fact, a genetic factor underpinning NAFLD has been suggested by familial aggregation studies, [8] heritability studies, [9] candidate gene studies, [3] genome-wide scans [10] and expression studies. [11] The probing into the genetics of NAFLD will help in the identification of individuals at risk, understanding NAFLD pathogenesis and developing new therapies. APO lipoprotein (APO) C-III, a protein produced by the liver [12], is an essential constituent of VLDL and HDL [13]. Considering the inhibitory effect of APOC-III on lipoprotein lipase (LPL) activity and hepatic uptake of lipoproteins [14], reports of APOC-III gene variants have been proposed as being potentially responsible for the occurrence of lipoprotein lipid profile disturbances. Accordingly, numerous polymorphisms in the APOC-III gene have been identified. [15] The aim of this work is to investigate the association of APO lipoprotein $\mathrm{C} 3$ Gene variants with nonalcoholic fatty liver disease in Egyptian patients.

\section{Subjects and Methods}

This study has involved 100 subjects affected with NAFLD, recruited from the Department of Obesity and Diabetes; Internal Medicine Specialized Hospital, Mansoura University, Egypt. The patients were selected randomly of those being overweight or obese with a BMI at least $>27$ and an ultrasound diagnosis of NAFLD after exclusion of other causes of steatohepatitis such as diabetes mellitus, hypothyroidism, nephrotic syndrome, pregnancy and alcohol intake. Their age mean \pm SD was $45.4 \pm 15.2$ years. They were in the form of $40(40 \%)$ males and $60(60 \%)$ females. Cased were characterized according to the scores given by the World Health Organization (WHO), Adult treatment panels (ATP) and
International Diabetic Federation (IDF) [16].

For comparison, negative control group was selected including 83 healthy non-obese unrelated subjects. For all participants, the levels of total cholesterol, triglyceride (TG), high density lipoprotein cholesterol (HDL-C), low density lipoprotein (LDL-C), were determined by enzymatic methods. Serum alanine aminotransferase (ALT), aspartate aminotransferase (AST), fasting and postprandial blood sugar, HBA1c and other parameters were carried out according to validated methods. DNA extraction was carried out for all participants using the generation DNA purification capture column kit (Gentra system, USA) which is based on a proprietary system that uses two reagents, a DNA purification solution and a DNA elution solution, along with a specially formulated purification matrix. SNPs in APOC3 gene, APOC3 -455T $>\mathrm{C}$ (rs2854116) and APOC3 -482C $>\mathrm{T}$ (rs2854117) were genotyped using polymerase chain reaction-restriction fragment length polymorphism (PCR RFLP) method [17]. Primers used for DNA amplification were: forward: 5'-GGCTGTGAGAGCTCAGCCCT-3' and reverse: 5' TCACACTGGAATTTCAGGCC-3'. The amplified 196 bp PCR product was digested with MspI enzyme to genotype polymorphism C-482T, and Fok I enzyme for SNP, APOC3 -455T >C (Fermentas, Fast Digest) by incubating at $37^{\circ} \mathrm{C}$ for $5 \mathrm{~min}$ followed by separation of fragments on 3\%agarose gel. The digestion with MspI enzyme for $-482 \mathrm{C}$ indicated by complete digestion into two bands of 143 and $53 \mathrm{bp}$ whereas, "T" allele, shows two bands of 159 and $37 \mathrm{bp}$. Heterozygous $-482 \mathrm{C} / \mathrm{T}$ genotype was detected by four bands of 159, 143, 53 and 37 bp. Restriction digestion with FokI enzyme showed no digestion for $-455 \mathrm{C}$ allele and PCR amplicon (196 bp) was left undigested. PCR product was digested into two bands of 133 and $63 \mathrm{bp}$ for $-455 \mathrm{~T}$ allele and for heterozygous and it results to three bands of 196, 133 and $63 \mathrm{bp}$.

\section{Statistical analysis}

Statistical analysis of data was done using the software statistical package SPSS program version 17. Student t-test was used to compare the numerical values related to lipid profile, other chemical parameters and body mass index whereas chi square, Fisher exact and odds ratio -with 95\% confidence interval- were used to compare frequencies of different genotypes and alleles among cases and controls. Hardy-Weinberg equilibrium (HWE) law was used to test the concordance of expected genotype frequencies to the observed ones using the chi square test.

\section{Results}

Cases and controls showed a non-significant difference regarding their age and gender ratio. However, cases showed significant lower levels of hemoglobin, red cell count, platelet count, serum albumin, and HDL together with significant higher levels of white cell count, creatinine level, sGOT, serum bilirubin, fasting and postprandial blood sugar, HbA1C level, CPK, cholesterol, LDL and TG levels (Table 1). 


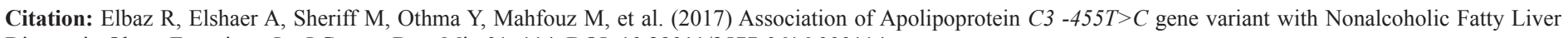
Disease in Obese Egyptians. Int J Genom Data Min 01: 114. DOI: 10.29011/2577-0616.000114

\begin{tabular}{|c|c|c|c|}
\hline & Cases & Controls & \multirow{2}{*}{ p } \\
\hline & 100 & 83 & \\
\hline \multirow[t]{2}{*}{ Male/Female } & $40 / 60$ & $30 / 53$ & 0.35 \\
\hline & Mean \pm SD & Mean \pm SD & \\
\hline AGE (year) & $45.45 \pm 15.29$ & $45.55 \pm 15.53$ & 0.964 \\
\hline HB (gram\%) & $11.31 \pm 1.74$ & $13.37 \pm 1.93$ & $.000^{* *}$ \\
\hline RBCs (million/ml) & $3.77 \pm .61$ & $4.77 \pm .31$ & $.000^{* *}$ \\
\hline $\begin{array}{c}\text { WBCs (thousand/ } \\
\text { ml) }\end{array}$ & $6.28 \pm 2.31$ & $5.46 \pm 1.34$ & $.005^{*}$ \\
\hline $\begin{array}{c}\text { Platelets (thousand/ } \\
\text { ml) }\end{array}$ & $167.69 \pm 62.75$ & $197.53 \pm 49.74$ & $.001^{*}$ \\
\hline Creatinine (mg\%) & $.98 \pm .25$ & $.66 \pm .26$ & $.000^{* *}$ \\
\hline sGPT (IU/L) & $38.71 \pm 43.48$ & $31.52 \pm 8.04$ & 0.139 \\
\hline sGOT (IU/L) & $43.07 \pm 38.97$ & $29.98 \pm 6.71$ & $.003^{*}$ \\
\hline Bilirubin (mg\%) & $1.29 \pm 1.29$ & $.90 \pm .14$ & $.006^{*}$ \\
\hline Albumin (gram\%) & $3.81 \pm .51$ & $4.27 \pm .49$ & $.000^{* *}$ \\
\hline FBS (mg\%) & $131.83 \pm 56.25$ & $80.96 \pm 9.31$ & $.000^{* *}$ \\
\hline PBS (mg\%) & $223.23 \pm 114.65$ & $127.81 \pm 23.39$ & $.000^{* *}$ \\
\hline HBA1c (gram\%) & $7.00 \pm 2.01$ & $4.90 \pm .38$ & $.000^{* *}$ \\
\hline CPK (IU/L) & $156.75 \pm 53.03$ & $75.94 \pm 13.41$ & $.000^{* *}$ \\
\hline $\begin{array}{c}\text { Total Cholesterol } \\
\text { (mg\%) }\end{array}$ & $230.37 \pm 48.58$ & $82.89 \pm 16.23$ & $.000^{* *}$ \\
\hline LDL (mg\%) & $153.05 \pm 34.31$ & $83.98 \pm 10.99$ & $.000^{* *}$ \\
\hline HDL (mg\%) & $54.89 \pm 11.44$ & $60.96 \pm 6.99$ & $.000^{* *}$ \\
\hline TG (mg\%) & $131.43 \pm 72.92$ & $78.49 \pm 14.87$ & $.000^{* *}$ \\
\hline \multicolumn{4}{|c|}{$\begin{array}{c}\text { SGPT: Serum glutamic pyruvic transaminase, sGOT: Serum } \\
\text { glutamic oxaloacetic transaminase, FBS: fasting blood sugar, PBS: } \\
\text { postprandial blood sugar, CPK: creatine phosphokinase, } \mathrm{LDL}= \\
\text { low-density lipoprotein cholesterol, } \mathrm{HDL}=\text { high-density lipoprotein, } \\
\mathrm{TG}=\text { triglyceride, }{ }^{*} \mathrm{p}=<0.05 \text { (significant), }{ }^{* *} \mathrm{p}=<0.001 \text { (extremely } \\
\text { significant) }\end{array}$} \\
\hline
\end{tabular}

Table 1: Demographic, clinical and chemical data of cases of fatty liver compared to controls.
Regarding gene polymorphism, cases showed a significantly higher frequency of the APOC3 $-455 \mathrm{CC}$ genotype than controls $(32 \%$ vs. $9.6 \%, p=0.0003$, Odds ratio $=5.33,95 \% \mathrm{CI}=2.2-12.7)$. Also, the frequency of the rare APOC $3-455 \mathrm{C}$ allele was significantly higher among cases than controls $(51 \%$ vs. $30.72 \%, p=0.0001$, $\mathrm{OR}=2.35,95 \% \mathrm{CI}=1.5-3.6)$. Hardy Weinberg equilibrium testing showed a non-significant level among controls denoting that the observed genotype frequencies were conforming to the expected ones. On the contrary cases have shown a significant difference between the observed and expected frequencies due to an increase of the rare genotypes and alleles (Table 2). On the other hand, cases showed a non-significant difference from controls regarding all frequencies of APOC3 $-482 \mathrm{C}>\mathrm{T}$ genotypes (CT vs. CC, TT vs. $\mathrm{CC}$ and $\mathrm{CT}+\mathrm{TT}$ vs. CC) as well as APOC3 $-482 \mathrm{~T}$ vs. $\mathrm{C}$ allele frequency. Hardy Weinberg equilibrium showed a significant difference of the observed genotype frequencies from that the expected ones for both cases and controls probably due to increased rare allele homozygosity (TT) in both groups.

\begin{tabular}{|c|c|c|c|c|c|}
\hline & Cases & Controls & p & $\begin{array}{c}\text { Odds } \\
\text { ratio }\end{array}$ & $\begin{array}{c}95 \% \\
\text { CI }\end{array}$ \\
\hline & N (\%) & $\mathrm{N}(\%)$ & & & \\
\hline \multicolumn{6}{|l|}{ C-482T } \\
\hline $\mathrm{CC}$ & $40(40.0)$ & $34(41.0)$ & Reference & & \\
\hline$\overline{C T}$ & $35(35.0)$ & $30(36.1)$ & 0.88 & 0.99 & $0.5-1.9$ \\
\hline TT & $25(25.0)$ & $19(22.9)$ & 0.92 & 1.12 & $0.5-2.4$ \\
\hline $\mathrm{CT}+\mathrm{TT}$ & $60(60.0)$ & $49(59.0)$ & 0.98 & 1.04 & $0.6-1.9$ \\
\hline $\mathrm{C}$ allele & $\begin{array}{c}115 \\
(57.50)\end{array}$ & $98(59.04)$ & Reference & & \\
\hline $\mathbf{T}$ allele & $85(42.50)$ & $68(40.96)$ & 0.85 & 1.07 & $0.7-1.6$ \\
\hline HWE & $\mathrm{p}<0.001^{* *}$ & $\mathrm{p}<0.001^{* *}$ & & & \\
\hline \multicolumn{6}{|l|}{$\mathrm{T}-455 \mathrm{C}$} \\
\hline TT & $30(30.0)$ & $40(48.2)$ & Reference & & \\
\hline TC & $38(38.0)$ & $35(42.2)$ & 0.35 & 1.45 & $0.7-2.8$ \\
\hline $\mathrm{CC}$ & $32(32.0)$ & $8(9.6)$ & $0.0003^{* *}$ & 5.33 & $\begin{array}{l}2.2- \\
12.7\end{array}$ \\
\hline $\mathrm{TC}+\mathrm{CC}$ & $70(70.0)$ & $43(51.8)$ & $0.018^{*}$ & 2.17 & $1.2-4.0$ \\
\hline $\mathrm{T}$ allele & $98(49.0)$ & $115(69.28)$ & Reference & & \\
\hline $\mathrm{C}$ allele & $102(51.0)$ & $51(30.72)$ & $0.0001^{* *}$ & 2.35 & $1.5-3.6$ \\
\hline HWE & $\mathrm{p}<0.05^{*}$ & $\mathrm{p}>0.05$ & & & \\
\hline $\mathrm{H}$ & $\begin{array}{l}\text { Vein } \\
<\end{array}$ & $\begin{array}{l}\text { Euilibriu } \\
\text { (extreme }\end{array}$ & $\begin{array}{l}=<0.05 \\
\text { gnificant) }\end{array}$ & . & ${ }^{* *} \mathrm{p}=$ \\
\hline
\end{tabular}

Table 2: The distribution of genotype and allelic frequency of SNP, $\mathrm{C}-482 \mathrm{~T}$ and APOC $3-455 \mathrm{~T}>\mathrm{C}$ of APOC3 gene between patients with nonalcoholic fatty liver disease and controls.

Comparing cases of fatty liver carrying the rare alleles of APOC3 gene (-482T and $-455 \mathrm{C})$ vs. others showed that the he distribution of BMI values, hematologic, liver function, renal function and lipid parameters were nearly similar denoting that 


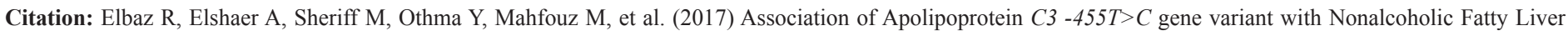
Disease in Obese Egyptians. Int J Genom Data Min 01: 114. DOI: 10.29011/2577-0616.000114

these polymorphisms might not be correlated to the degree of affection of liver function, lipid and other blood profiles (Table 3, 4).

\begin{tabular}{|c|c|c|c|c|c|}
\hline & & \multicolumn{2}{|c|}{ APOC3 T-455C } & \multicolumn{2}{|c|}{ APOC3 C-482T } \\
\hline \multirow{2}{*}{ BMI grade } & & TT & $\mathrm{TC}+\mathrm{CC}$ & $\mathrm{CC}$ & $\mathrm{CT}+\mathrm{TT}$ \\
\hline & & n (\%) & n (\%) & n (\%) & n (\%) \\
\hline $25.0-29.9$ & overweight & $0(.0)$ & $1(1.4)$ & $0(.0)$ & $1(1.7)$ \\
\hline $30.0-34.9$ & class I obesity & $5(16.7)$ & $19(27.1)$ & $10(25.0)$ & $14(23.3)$ \\
\hline $35.0-39.9$ & class II obesity & $9(30.0)$ & $20(28.6)$ & $12(30.0)$ & $17(28.3)$ \\
\hline $40.0-49.9$ & class III obesity & $16(53.3)$ & $22(31.4)$ & $15(37.5)$ & $23(38.3)$ \\
\hline $50.0-59.9$ & class IV obesity & $0(.0)$ & $8(11.4)$ & $3(7.5)$ & $5(8.3)$ \\
\hline Chi-Square $\left(\mathrm{X}^{2}\right)$ & & $\mathrm{p}=0.112$ & & $\mathrm{p}=0.946$ & \\
\hline
\end{tabular}

Table 3: Distribution of BMI between cases carrying the rare allele of APOC $3-455 \mathrm{~T}>\mathrm{C}$ of APOC 3 gene $(\mathrm{TC}+\mathrm{CC})$ vs. cases carrying the TT genotype.

\begin{tabular}{|c|c|c|c|c|c|c|}
\hline & \multicolumn{2}{|c|}{ APOC3C-482T } & & \multicolumn{2}{|c|}{ APOC $3-455 T>C$} & \\
\hline & $\mathrm{CC}$ & $\mathrm{CT}+\mathrm{TT}$ & & TT & $\mathrm{TC}+\mathrm{CC}$ & \\
\hline & $(n=40)$ & $(n=60)$ & & $(\mathrm{n}=30)$ & $(n=70)$ & \\
\hline & Mean \pm SD & Mean \pm SD & $\mathrm{P}$ & Mean \pm SD & Mean \pm SD & $\mathrm{p}$ \\
\hline HB (gram\%) & $11.17 \pm 1.86$ & $11.39 \pm 1.67$ & 0.54 & $11.25 \pm 1.85$ & $11.33 \pm 1.70$ & 0.84 \\
\hline RBCs (million/ml) & $3.74 \pm .58$ & $3.80 \pm .63$ & 0.65 & $3.79 \pm .57$ & $3.77 \pm .62$ & 0.83 \\
\hline WBCs (thousand/ml) & $5.84 \pm 1.79$ & $6.57 \pm 2.58$ & 0.13 & $6.28 \pm 3.05$ & $6.27 \pm 1.94$ & 0.98 \\
\hline Platelets (thousand/ml) & $161.3 \pm 49.09$ & $171.97 \pm 70.48$ & 0.41 & $176.33 \pm 67.51$ & $163.99 \pm 60.73$ & 0.37 \\
\hline Creatinine (mg\%) & $.98 \pm .19$ & $.98 \pm .29$ & 0.96 & $.99 \pm .30$ & $.98 \pm .23$ & 0.69 \\
\hline sGPT (IU/L) & $41.03 \pm 62.07$ & $37.17 \pm 24.89$ & 0.67 & $33.77 \pm 20.50$ & $40.83 \pm 50.21$ & 0.46 \\
\hline sGOT (IU/L) & $42.30 \pm 51.17$ & $43.58 \pm 28.57$ & 0.87 & $44.37 \pm 31.81$ & $42.51 \pm 41.86$ & 0.83 \\
\hline Bilirubin (mg\%) & $1.32 \pm 1.58$ & $1.28 \pm 1.07$ & 0.87 & $1.05 \pm .44$ & $1.40 \pm 1.51$ & 0.22 \\
\hline Albumin (gram\%) & $3.74 \pm .52$ & $3.86 \pm .49$ & 0.23 & $3.84 \pm .55$ & $3.80 \pm .49$ & 0.74 \\
\hline FBS (mg\%) & $131.1 \pm 54.17$ & $132.30 \pm 58.04$ & 0.92 & $130.97 \pm 39.78$ & $132.20 \pm 62.23$ & 0.92 \\
\hline PBS (mg\%) & $228.3 \pm 120.17$ & $219.88 \pm 111.72$ & 0.72 & $225.17 \pm 91.68$ & $222.40 \pm 123.8$ & 0.91 \\
\hline Total Cholesterol (mg\%) & $232.6 \pm 49.06$ & $228.90 \pm 48.61$ & 0.71 & $236.17 \pm 41.20$ & $227.89 \pm 51.49$ & 0.44 \\
\hline LDL (mg\%) & $156.3 \pm 33.66$ & $150.92 \pm 34.85$ & 0.45 & $156.20 \pm 30.78$ & $151.70 \pm 35.84$ & 0.55 \\
\hline HDL (mg\%) & $54.70 \pm 11.33$ & $55.02 \pm 11.61$ & 0.89 & $56.07 \pm 9.01$ & $54.39 \pm 12.36$ & 0.5 \\
\hline
\end{tabular}




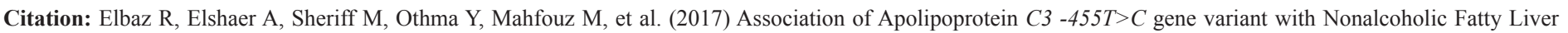
Disease in Obese Egyptians. Int J Genom Data Min 01: 114. DOI: 10.29011/2577-0616.000114

\begin{tabular}{|c|c|c|c|c|c|c|}
\hline TG (mg\%) & $135.3 \pm 74.58$ & $128.87 \pm 72.32$ & 0.67 & $143.33 \pm 71.68$ & $126.33 \pm 73.36$ & 0.29 \\
\hline HBA1c (gram\%) & $7.08 \pm 1.91$ & $6.95 \pm 2.08$ & 0.75 & $6.96 \pm 1.48$ & $7.02 \pm 2.20$ \\
\hline CPK (IU/L) & $152.6 \pm 47.28$ & $159.55 \pm 56.75$ & 0.52 & $166.97 \pm 56.80$ & $152.37 \pm 51.13$ & 0.21 \\
\hline BMI & $40.30 \pm 6.76$ & $40.03 \pm 6.41$ & 0.84 & $39.68 \pm 5.31$ & $40.34 \pm 7.00$ & 0.64 \\
\hline $\begin{array}{c}\text { sGPT: Serum glutamic pyruvic transaminase, sGOT: Serum glutamic oxaloacetic transaminase, FBS: fasting blood sugar, PBS: postprandial blood } \\
\text { sugar, CPK: creatine phosphokinase, LDL= low-density lipoprotein cholesterol, HDL: high-density lipoprotein, TG: triglyceride. }\end{array}$
\end{tabular}

Table 4: Distribution of hematologic, chemical and lipid parameters between cases carrying the rare allele of C-482T of APOC3 gene vs. others.

\section{Discussion}

Nonalcoholic fatty liver disease (NAFLD) is the most common liver disease in the world today. Hence, we were interested to study its underlying genetic basis -and to the first time- among Egyptian affected obese subjects. This study has shown that all patients were found to be also diabetic. This might confirm the hypothesis that insulin resistance might be a pathophysiological factor or "first hit" in the development of NAFLD [18]. These cases have shown a concurrent significant lower level of hemoglobin, red cell count, platelet count, serum albumin, and HDL together with a significant higher levels of white cell count, creatinine level, sGOT, serum bilirubin, fasting and post prandial blood sugar, HbA1C level, CPK, cholesterol, LDL and TG levels. Li MR et al. 2014 have reported that measurement values of BMI and lipid profile were significantly different between the control group and NAFLD group. They reported that obesity; elevated AST, low HDL, hypercholesterolemia, and hypertriglyceridemia were the most common characteristics in the NAFLD group [19]. The two SNPs in the promoter region of the APOC3 gene, rs2854117 and rs2854116 have been described to be associated with hypertriglyceridemia, metabolic syndrome and coronary artery disease [20]. More recently, these variants have been shown to be associated with the occurrence of NAFLD. Egyptian cases showed a significantly higher frequency of the APOC3 -455 CC genotype than controls. On the other hand, cases showed a nonsignificant difference regarding all APOC3 -482 C>T genotypes and alleles.

Interestingly, both polymorphisms showed no relation to patients' levels of BMI, hematologic, liver function, renal function and lipid parameters. Similarly, Li et al study on Chinese patients showed that APOC3 -455 T>C genotypes were associated with NAFLD after adjusting for age, gender, and BMI [19]. On the other hand, the study of Yu et al. 2010 on Chinese Han Population showed the rare variant APOC3 haplotype was associated with the risk of hypertriglyceridemia in individuals without T2DM but not in those with it [21]. In agreement with our results, Puppala et al., 2014 have reported that among Southern Indian patients, APOC3 -455 $\mathrm{T}>\mathrm{C}$ polymorphism was significantly associated with NAFLD with no significant association of the other $-482 \mathrm{C}>\mathrm{T}$ polymorphism. Genotype APO C3-455 CC genotype was associated significantly with the elevated serum triglycerides in patients [22]. Also, Petersen et al. 2010 reported that NAFLD was found in 38 $\%$ of the Indian men in association with rare variant APOC 3 alleles at one or both of these loci [23]. Researchers have proposed that the rare variant alleles led to increase in the amounts of APOC3 accompanied with inhibition of lipoprotein lipase activity and triglyceride clearance, resulting in hypertriglyceridemia due to increase in chylomicron remnants taken up by the liver resulting in NAFLD [24]. However, we might observe a different pattern related to ethnic origin particularly cases of European and American localities. So, to the contrary of our results, Richart and his colleagues 2010 found no relationship between APOC 3 mRNA expression and triglycerides content in the livers of morbidly obese women of European descent. Also, they did not find any association between gene expression and plasma triglyceride concentrations or insulin-resistance index [25]. Also, Sentinelli et al., 2011 in their study among Southern European patients found no significant association between APOC3 polymorphisms and fatty liver disease, lipids, and insulin-resistance in obese subjects [26] Hyysalo et al., 2012 [27] reported a similar lack of association between the APOC3 gene polymorphisms and NAFLD on their investigation of Finnish population. In their study, individuals with and without the variant alleles ( $-455 \mathrm{C},-482$ Tor both) had similar amounts of liver fat, plasma APOC3 concentrations, serum triglycerides, HDL and levels of fasting plasma glucose, insulin and transaminases. Furthermore, other subsequent studies in Hispanic, European American, African American and European subjects have failed to confirm the association of APOC3 variants with NAFLD [28]. Similarly, the study reported by Niu et al., 2014 on Chinese Han patients did not find significant associations between these polymorphisms and the risk of NAFLD [29]. These variations might be due to studied population diversity, epigenetic and environmental impact on gene expression. Although our study might suffer some limitations related to its relatively small sample size, including a sample of patients all being obese and diabetic, it mostly discerns a conclusion of a positive association of NAFLD in Egyptian obese cases with the APO C3 $-455 \mathrm{~T}>\mathrm{C}$ polymorphism and not with APOC3 $-482 \mathrm{C}>\mathrm{T}$ in APOC3 with no apparent impact on their levels of BMI, liver function and lipid profile. 


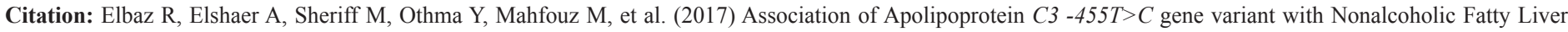
Disease in Obese Egyptians. Int J Genom Data Min 01: 114. DOI: 10.29011/2577-0616.000114

\section{Acknowledgement}

We would like to thank the staff members of the Department of Endocrinology and Diabetes, Mansoura University Hospitals, Mansoura, Egypt for their sincere help and cooperation.

\section{Conflict of Interest}

This work is completely free from all issues related to conflict of interest.

\section{References}

1. Lazo M, Clark JM (2008) The epidemiology of nonalcoholic fatty liver disease: a global perspective. Semin Liver Dis 28: 339-350.

2. Brunt EM (2001) Nonalcoholic steatohepatitis: definition and pathology. Semin Liver Dis 21: 3-16.

3. Day CP (1998) James of Steatohepatitis a tale of two "hits" Gastroenterology 114: 842-845.

4. Moreno-Sánchez D (2006) [Epidemiology and natural history of primary nonalcoholic fatty liver disease]. Gastroenterol Hepatol 29: 244-254.

5. Marchesini G, Marzocchi R (2007) Metabolic syndrome and NASH. Clin Liver Dis 11: 105-117.

6. Fabbrini E, Mohammed BS, Magkos F, Korenblat KM, Patterson BW, et al. (2008) Alterations in adipose tissue and hepatic lipid kinetics in obese men and women with nonalcoholic fatty liver disease. Gastroenterology 134: 424-431.

7. Tamura S (2005) Shimomura I. Contribution of adipose tissue and de novo lipogenesis to nonalcoholic fatty liver disease. J Clin Invest 115 $1139-1142$

8. Abdelmalek MF, Liu C, Shuster J, Nelson DR, Asal NR (2006) Familial aggregation of insulin resistance in firstdegree relatives of patients withnonalcoholic fatty liver disease. Clin Gastroenterol Hepatol 4: $1162-1169$

9. Brouwers MC, van Greevenbroek MM, Cantor RM, Shiehmorteza M, Yokoo T, et al. (2009) Heritability of nonalcoholic fatty liver disease. Gastroenterology 137: 1536.

10. Romeo S, Kozlitina J, Xing C, Pertsemlidis A, Cox D, et al. (2008) Genetic variation in PNPLA3 confers susceptibility to nonalcoholic fatty liver disease. Nat Genet 40: 1461-1465.

11. Caballero F, Fernández A, De Lacy AM, Fernández-Checa JC, Caballería J (2009) Enhanced free cholesterol, SREBP-2 and StAR expression in human NASH. J Hepatol 50: 789-796.

12. Shoulders CC, Grantham TT, North JD, Gaspardone A, Tomai F, et al. (1996) Hypertriglyceridemia and the apolipoprotein CIII gene locus: lack of association with the variant insulin response element in Italian school children. Hum Genet 98: 557-566.

13. Mahley RW, Innerarity TL, Rall SC Jr, Weisgraber KH (1984) Plasma lipoproteins: apolipoprotein structure and function. J Lipid Res 25: 1277-1294

14. McConathy WJ, Gesquiere JC, Bass H, Tartar A, Fruchart JC, et al. Inhibition of lipoproteilipase activity by synthetic peptides of apolipoprotein C-III. J Lipid Res 33: 995-1003.
15. Talmud PJ, Humphries SE (1997) Apolipoprotein C-III gene variation and dyslipidaemia. Curr Opin Lipidol 8: 154-158.

16. Alberti KG, Zimmet P, Shaw J (2005) IDF Epidemiology Task Force Consensus Group. The metabolic syndrome--a new worldwide definition. Lancet 366: 1059-1062.

17. Guettier JM, Georgopoulos A, Tsai MY, Radha V, Shanthirani S, et al. (2005) Mohan V. Polymorphisms in the fatty acid-binding protein 2 and apolipoprotein C-III genesare associated with the metabolic syndrome and dyslipidemia in a South Indianpopulation. J Clin Endocrinol Metab 90: 1705-1711.

18. Cortez-Pinto H, Camilo ME, Baptista A, De Oliveira AG, De Moura MC et al. (1999) Non-alcoholic fatty liver: another feature of the metabolic syndrome? Clin Nutr 18: 353-358.

19. Li MR, Zhang SH, Chao K, Liao XH, Yao JY, et al. (2014) Apolipoprotein C3 $(-455 \mathrm{~T}>\mathrm{C})$ polymorphism confers susceptibility to nonalcoholicfatty liver disease in the Southern Han Chinese population. World J Gastroenterol 38: 14010-14017.

20. Miller M, Rhyne J, Chen H, Beach V, Ericson R, et al. (2007) APOC3 promoter polymorphisms C-482T and T-455C are associated with the metabolic syndrome. Arch Med Res 38: 444-451.

21. Yu J, Wang H, Yang S, Yuan J, Chen L (2010) The Effect of APOC3 Promoter Polymorphisms on the Risk of Hypertriglyceridemia in Chinese Han Population with or Without Type 2 Diabetes Mellitus. Laboratory Medicine 41: 34-39.

22. Puppala J, Bhrugumalla S, Kumar A, Siddapuram SP, Viswa PD, et al. (2014) Apolipoprotein C3 gene polymorphisms in Southern Indian patients with nonalcoholic fatty liver disease. Indian J Gastroenterol 33: 524-529.

23. Petersen KF, Dufour S, Hariri A, Nelson-Williams C, Foo JN, et al. (2010) Apolipoprotein C3 gene variants in nonalcoholic fatty liver disease. N Engl J Med 362: 1082-1089.

24. Ito Y, Azrolan N, O'Connell A, Walsh A, Breslow JL, et al. (1990) Hypertriglyceridemia as a result of human apo CIII gene expression in transgenic mice. Science 249: 790-793.

25. Richart C, Auguet T, Terra X (2010) Apolipoprotein C3 gene variants in nonalcoholic fatty liver disease. N Engl J Med 363: 193-194.

26. Sentinelli F, Romeo S, Maglio C, Incani M, Burza MA, et al. (2011) Lack of effect of apolipoprotein C3 polymorphisms on indices of liver steatosis, lipid profile and insulin resistance in obese Southern Europeans. Lipids Health Dis 10: 93.

27. Hyysalo J, Stojkovic I, Kotronen A, Hakkarainen A, Sevastianova K, et al. (2012) Genetic variation in PNPLA3 but not APOC3 influences liver fat in non-alcoholic fatty liver disease. J Gastroenterol Hepatol 27: 951-956.

28. Valenti L, Nobili V, Al-Serri A, Rametta R, Leathart JB, et al. (2011) Day $\mathrm{CP}$. The APOC3 T-455C and C-482T promoter region polymorphisms are not associated with the severity of liver damage independently of PNPLA3 I148M genotype in patients with nonalcoholic fatty liver. J Hepatol 55: 1409-1414.

29. Niu TH, Jiang M, Xin YN, Jiang XJ, Lin ZH, et al. (2014) Lack of association between apolipoprotein $\mathrm{C} 3$ gene polymorphisms and risk of nonalcoholic fatty liver disease in a Chinese Han population. World $\mathrm{J}$ Gastroenterol 20: 3655-3662. 